\title{
Current perspectives on combination therapy in the management of hypertension
}

\author{
This article was published in the following Dove Press journal: \\ Integrated Blood Pressure Control \\ 16 June 2013 \\ Number of times this article has been viewed
}

\author{
Samir G Mallat \\ Houssam S Itani \\ Bassem Y Tanios \\ American University of Beirut, \\ Department of Internal Medicine, \\ Division of Nephrology and \\ Hypertension, Beirut, Lebanon
}

Correspondence: Samir G Mallat Department of Internal Medicine, American University of Beirut Medical Center, PO Box I I-0236, Riad El-Solh I 107 2020, Beirut, Lebanon

Tel +96। I 350000

Fax +96I I37 0814

Email samir.mallat@aub.edu.lb
Abstract: Hypertension (HTN) is a worldwide health problem and a major preventable risk factor for cardiovascular (CV) events. Achieving an optimal blood pressure (BP) target for patients with HTN will often require more than one BP-lowering drug. Combination therapy is not only needed, but also confers many advantages such as better efficacy and a better tolerability. A better compliance and simplicity of treatment is noted with the single-pill combination (SPC). In addition, for those patients who do not achieve BP target when receiving dual combinations, triple SPCs are now available, and their efficacy and safety have been tested in large clinical trials. BP-lowering drugs used in combination therapy should have complementary mechanisms of action, leading to an additive BP-lowering effect and improvement in overall tolerability, achieved by decreasing the incidence of adverse effects. On the basis of large, outcome-driven trials, preferred dual combinations include an angiotensin receptor antagonist (ARB) or an angiotensin converting enzyme inhibitor (ACEI) combined with a calcium channel blocker (CCB), or an ARB or ACEI combined with a diuretic. Acceptable dual combinations include a direct rennin inhibitor (DRI) and a CCB, a DRI and a diuretic, a beta-blocker and a diuretic, a $\mathrm{CCB}$ and a diuretic, a $\mathrm{CCB}$ and a beta-blocker, a dihydropyridine $\mathrm{CCB}$ and a non-dihydropyridine $\mathrm{CCB}$, and a thiazide diuretic combined with a potassium-sparing diuretic. Some combinations are not recommended and may even be harmful, such as dual renin angiotensin aldosterone system inhibition. Currently available triple SPCs combine a renin angiotensin aldosterone system inhibitor with a CCB and a diuretic. Combination therapy as an initial approach is advocated in patients with a systolic BP more than $20 \mathrm{mmHg}$ and/or a diastolic BP more than $10 \mathrm{mmHg}$ above target and in patients with high CV risk. In addition, using SPCs has been stressed and favored in recent international guidelines. Recently, triple SPCs have been approved and provide an attractive option for patients not achieving BP target on dual combination. The effect of such a strategy in the overall management of HTN, especially on further reducing the incidence of $\mathrm{CV}$ events, will have to be confirmed in future clinical and population-based studies.

Keywords: hypertension, combination therapy, single pill, dual combination, triple combination

\section{Introduction}

Hypertension (HTN) is a highly prevalent disease estimated to be found in around 26\% of the adult population worldwide. ${ }^{1}$ In the United States, it is estimated that about $30 \%$ of adults have HTN, as defined by a systolic blood pressure (BP) of $140 \mathrm{mmHg}$ or higher, a diastolic BP of $90 \mathrm{mmHg}$ or higher, or the current use of a BP-lowering drug. Furthermore, among persons aged 65 years or older, the prevalence reached $70 \%{ }^{2}$

HTN remains one of the major preventable risk factors for coronary events, stroke, heart failure, peripheral vascular disease, and progression of kidney disease..$^{3-6}$ 
Despite recent advances in therapy and increased awareness among both physicians and patients, a large proportion of the hypertensive population continues to have suboptimal BP control, although it is improved when compared with previous data. ${ }^{2,7}$

To achieve optimal, guideline-recommended BP targets, most hypertensive patients will require a combination of two or more BP-lowering drugs, and monotherapy would likely be sufficient only in a small proportion of patients (about 20\%-30\%). ${ }^{8}$

Recent international guidelines recommend initiating a two-drug combination therapy both for patients with a systolic BP more than $20 \mathrm{mmHg}$ and/or a diastolic BP more than $10 \mathrm{mmHg}$ above target and for patients with high cardiovascular (CV) risk. ${ }^{9,10}$ In addition, single-pill combination (SPC) drugs (SPCs) have also gained ground as the preferred approach to combine BP-lowering drugs in recently updated European guidelines. ${ }^{11}$

In this article, we review the latest approach to the management of HTN in light of recent advances in combination therapy.

\section{Why is combination therapy needed?}

The concept of monotherapy up-titration to achieve BP target has been repetitively challenged. ${ }^{12}$ Such a strategy is unlikely to achieve the same BP-lowering effect in comparison with combination therapy, as demonstrated in many studies. In a recent meta-analysis, the BP-lowering effect of combining drugs from two different classes was five times more than doubling the dose of a single drug. ${ }^{13}$ In addition, in a recent retrospective study, hypertensive patients initially begun on combination therapy were more likely to achieve their BP target at 12 months compared with those started on monotherapy. ${ }^{14}$

One pivotal point in treating $\mathrm{HTN}$ in patients with high $\mathrm{CV}$ risk is the time to achieve optimal BP control. As demonstrated in a post hoc analysis of the Valsartan Antihypertensive LongTerm Use Evaluation (VALUE) trial, patients who achieved BP target at 6 months had fewer subsequent $\mathrm{CV}$ events. Furthermore, an earlier BP response within 1 month was predictive of better outcomes. ${ }^{15}$ A possible explanation for this finding is that patients who achieved slower BP control might have started with a higher $\mathrm{CV}$ risk. As demonstrated in a retrospective analysis by Nasser et al, ${ }^{16}$ the patients with a higher baseline CV risk (a higher amount of albuminuria, diabetes mellitus, and obesity and a lower estimated glomerular filtration rate) were those who attained BP goals slower. In the same study, it was also shown that therapeutic inertia played an important role, emphasizing the pivotal influence of caring physicians on the speed to BP control. In a recent, randomized controlled trial in patients with HTN and metabolic syndrome, initiating therapy with a combination of an angiotensin receptor antagonist (ARB; valsartan [VAL]) and a calcium channel blocker (CCB; amlodipine [AML]) achieved BP target more rapidly than a strategy starting with a high dose of monotherapy with VAL. ${ }^{17}$ Moreover, in a recent matched cohort study in patients with HTN, initial combination therapy was associated with a $34 \%$ risk reduction in $\mathrm{CV}$ events compared with monotherapy, and a more rapid achievement of BP target was the main contributor to this risk reduction. ${ }^{18}$

Therefore, it is essential and currently recommended that patients with a systolic BP more than $20 \mathrm{mmHg}$ and/or a diastolic BP more than $10 \mathrm{mmHg}$ above target and/or high $\mathrm{CV}$ risk (ie, patients with established $\mathrm{CV}$ disease or those with multiple CV risk factors such as metabolic syndrome, subclinical organ damage, diabetes, and renal disease) be initiated on combination therapy at diagnosis. ${ }^{9,10}$

In addition, recent data suggest that initiation of a combination therapy for patients with uncomplicated stage $1 \mathrm{HTN}$ (systolic BP between 140 and $159 \mathrm{mmHg}$ and/or diastolic BP between 90 and $99 \mathrm{mmHg}$ ) might be more effective at achieving BP target than up-titrating monotherapy. In a meta-analysis of nine randomized controlled trials that included both stage 1 and stage 2 hypertensive patients, $92 \%$ of patients with stage $1 \mathrm{HTN}$ randomly assigned to receive a fixed combination of VAL/ hydrochlorothiazide (HCTZ) (160 mg/12.5 mg) achieved their BP target at week 8 versus $74.7 \%$, using a higher dose of VAL (320 mg). ${ }^{19}$ In fact, in a recent position paper, the American Society of HTN suggested starting with a combination therapy in patients with uncomplicated stage 1 HTN, in particular when one agent will improve the adverse effects profile of the other. ${ }^{20}$

Another important aspect in HTN management is BP variability. Evidence from animal studies suggests that combination therapy is superior to monotherapy in reducing BP variability and may be the preferred approach in this setting. ${ }^{21,22}$ In an analysis of trials comprising cohorts with previous transient ischemic attack, visit-to-visit systolic BP fluctuations and maximum systolic BP correlated with increased risk for stroke and coronary events. ${ }^{23}$

Furthermore, monotherapy may fail in controlling BP by triggering a counter-regulatory reaction, diminishing its BP-lowering effect. This reaction can be blocked by a proper combination therapy that will act on several mechanisms involved in the pathophysiology of HTN. ${ }^{24}$ 
Finally, high doses of monotherapy may lead to a better control of BP at the expense of increasing the incidence of adverse effects. When combining two drugs from different classes, lower dosages of the individual components will be enough to achieve BP target with fewer dose-related adverse effects. ${ }^{25}$ In addition, each agent in the combination can counterbalance the adverse effects of the other. ${ }^{26}$

\section{Which is better, SPC or free combination?}

An important question that arises is whether combination therapy should be delivered as a free combination or as a SPC.

In general, whether used as free combination or SPC, combination therapy achieves an equivalent BP-lowering effect. ${ }^{27,28}$ A 2004 study demonstrated that an SPC composed of the ARB candesartan and HCTZ was equally safe and effective at reducing $\mathrm{BP}$ when compared with the addition of HCTZ to previous monotherapy as a free combination. ${ }^{29}$

However, SPCs offer several advantages compared with a free combination. In a recent meta-analysis, SPCs significantly improved compliance and persistence to therapy compared with corresponding free combinations of the same drugs. It would be logical to extrapolate from this data that because compliance is improved, overall efficacy and BP control would be better when using SPCs. In fact, in the same meta-analysis, using SPCs demonstrated trends toward better BP control and decreased incidence of adverse effects compared with a free combination..$^{30}$ In a retrospective study, significantly more patients adhered to a prescribed single pill of enalapril/HCTZ at 12 months than to a free combination of the same drugs. ${ }^{31}$ Previous data have clearly shown that increasing the number of pills had a negative effect on compliance and on persistence on therapy, translating into poor clinical outcomes. ${ }^{32-34}$

On another note, to achieve BP targets, up to $24 \%$ to $32 \%$ of patients will require three or more drugs, as shown in clinical trials. ${ }^{35,36}$ SPCs have the potential to simplify the complex task of combining and titrating drugs from several classes. ${ }^{37}$

Currently available SPC formulations offer a wide range of dosages for the individual components, offering good flexibility for dosage adjustment and titration for optimal BP control. Triple-combination formulations are also emerging and may additionally offer the advantage of further reducing the pill burden. ${ }^{38}$

Therefore, SPCs clearly offer all the advantages of free combination drugs in addition to improved adherence, simplification of therapy, better efficacy, and better tolerability. In addition, they are currently endorsed by international guidelines as the preferred strategy to combine BP-lowering drugs. ${ }^{11,20}$

Table 1 illustrates a comparison between different HTN management strategies.

\section{What is required for combination therapy?}

HTN is a complex disease in which multiple factors and physiological mechanisms are involved. The primary hemodynamic parameters for BP regulation are intravascular volume, cardiac output, and systemic vascular resistance. The renin angiotensin aldosterone system (RAAS) and the sympathetic nervous system are the the fine-tuners that continuously both regulate and calibrate these parameters. ${ }^{39}$

Most commonly used BP-lowering drugs include diuretics, beta-adrenoceptor antagonists (beta-blockers), CCBs, angiotensin converting enzyme inhibitors (ACEIs), ARBs, direct renin inhibitors (DRIs), alpha-blockers, and centrally acting agents. Therefore, the possibility of combining drugs is quite large. However, not every combination is beneficial, and some combinations can be potentially dangerous.

For instance, combining a beta-blocker with a centrally acting agent (clonidine, alpha-methyldopa) can lead to bradycardia and heart block, and their abrupt withdrawal

Table I Comparison between different HTN management strategies ${ }^{13-37}$

\begin{tabular}{|c|c|c|c|c|}
\hline & Low-dose monotherapy & High-dose monotherapy & Free combination therapy & $\begin{array}{l}\text { Single-pill combination } \\
\text { therapy }\end{array}$ \\
\hline Efficacy & - & + & ++ & ++ \\
\hline Time to reach BP target & - & + & ++ & ++ \\
\hline $\mathrm{BP}$ variability & - & - & + & + \\
\hline Simplicity & + & + & - & + \\
\hline Flexibility & + & + & + & + \\
\hline Compliance & + & + & - & + \\
\hline Tolerability & + & - & + & ++ \\
\hline
\end{tabular}

Abbreviations: HTN, hypertension; BP, blood pressure. 
can result in a hypertensive crisis. ${ }^{20,40}$ In addition, in the ONgoing Telmisartan Alone and in combination with Ramipril Global Endpoint Trial (ONTARGET), the combination of an ACEI and an ARB leads to increased incidence of adverse effects with no improvement in outcomes, and in the recently halted Aliskiren Trial In Type 2 Diabetes Using Cardio-Renal Disease Endpoints (ALTITUDE) trial, the addition of the DRI to an ARB resulted in increased incidence of hypotension, renal impairment, and hyperkalemia, which might have accounted for the significantly higher incidence of cardiac arrest in the combination therapy group. ${ }^{41,42}$ In addition, the use of beta-blockers with a nondihydropyridine CCB (such as verapamil) can lead to potentiation of the negative inotropic and chronotropic effect of these drugs. ${ }^{43}$

Similarly, some classes of drugs should not be combined because they can antagonize each other; for example, combining an $\alpha 1$-antagonist (ie, doxazosin) with a sympathetic modulator $\alpha$-agonist (ie, clonidine). ${ }^{43}$

Therefore, drug combinations in HTN must fulfill certain requirements to be approved for use. First, the agents to combine should have an additive BP-lowering effect by acting on complementary mechanisms involved in the pathogenesis of HTN and blocking the counter-regulatory pathways triggered by one another. ${ }^{25}$ For example, diuretics and CCBs will activate RAAS; therefore, the addition of a RAAS inhibitor to any of these agents will lead to potentiation of their BP-lowering effect. ${ }^{44,45}$ The same rationale applies to the combination of a beta-blocker with a diuretic where the BP-lowering effect will also be additive, as beta-blockers also inhibit the RAAS. ${ }^{46}$ Another example to illustrate this complementary action is the beta-blocker/CCB combination. On one hand, the CCB-induced activation of the sympathetic nervous system can be blunted by the beta-blocker effect, but on the other hand, the alpha-mediated reflex vasoconstriction induced by beta-blockers can be attenuated by the vasodilatory effect of the CCB. ${ }^{47,48}$ In contrast, and because of the overlap in their mechanism of action (RAAS inhibition), the combination of a RAAS inhibitor with a beta-blocker is not recommended for management of HTN, as this combination will produce only a modest incremental BP-lowering effect. ${ }^{49}$ However, these agents are commonly combined and are recommended in patients with heart failure and in those who suffered a myocardial infarction because of their established effects in reducing mortality in these populations..$^{50,51}$

Second, each agent of the combination therapy should neutralize the adverse effects of the other, thus improving the overall tolerability. A CCB-induced peripheral edema secondary to arteriolar vasodilation can be attenuated by the postcapillary venodilation exerted by the RAAS inhibitor. ${ }^{26,52}$ Similarly, thiazide diuretic-induced hypokalemia can be counterbalanced by addition of a RAAS inhibitor or a potassium-sparing diuretic such as amiloride, triamterene or spironolactone. ${ }^{44,53}$ More importantly, the choice of components for any combination therapy should be based on the best available evidence from clinical trials concerning their efficacy in achieving optimal BP targets with a beneficial effect on $\mathrm{CV}$ outcomes.

\section{Specific combinations}

As stated earlier, not all combinations are equal, and international guidelines classify various combinations as preferred, acceptable, or not acceptable on the basis of large, outcome-driven clinical trials on safety and on the efficacy of the combination (Table 2). ${ }^{10,20}$

\section{Preferred combinations \\ RAAS inhibitors-CCB}

The addition of an ACEI, ARB, or DRI to a CCB has a fully additive BP-lowering effect. ${ }^{24}$ The superiority of this specific combination in reducing $\mathrm{CV}$ events has been illustrated in several clinical trials.

In the Anglo-Scandinavian Cardiac Outcomes TrialBlood Pressure Lowering Arm (ASCOT-BPLA) trial, 19,257 patients with HTN and at least three CV risk factors were randomly assigned to receive either AML, adding an ACEI (perindopril) as required, versus atenolol, adding bendroflumethiazide (diuretic) as required. After 5.5 years of

Table 2 Combination therapy in $\mathrm{HTN}^{10,20,40-70}$

\begin{tabular}{lll}
\hline Preferred & Acceptable & Not acceptable \\
\hline ACEl or ARB/ & Beta-blocker/diuretic & Dual RAAS inhibition \\
DHP CCB & & \\
ACEl or ARB/ & DHP CCB/diuretic & RAAS inhibitor/ \\
diuretic & & beta-blocker \\
& DHP CCB/beta-blocker & Non-DHP CCB/ \\
& & beta-blocker \\
& Thiazide diuretic/ & Centrally acting agent/ \\
& potassium-sparing diuretic & beta-blocker \\
& DHP CCB/non-DHP CCB & \\
& DRI/DHP CCB & \\
& DRI/diuretic & \\
& RAAS inhibitor/non-DHP CCB & \\
\hline
\end{tabular}

Note: Adapted from Journal of the American Society of Hypertension, Vol 4 Issue I, Alan H Gradman, Jan N Basile, Barry L Carter, George L Bakris, Combination therapy in hypertension 42-50, Copyright 2010, with permission from Elsevier. Abbreviations: HTN, hypertension; ACEl, angiotensin-converting enzyme inhibitor; $A R B$, angiotensin receptor blocker; DHP, dihydropyridine; CCB, calcium channel blocker; RAAS, Renin angiotensin aldosterone system; DRI, direct renin inhibitor. 
follow-up, the trial was halted early, as there was a significant $26 \%$ reduction in all $\mathrm{CV}$ events, $23 \%$ reduction in stroke, and $11 \%$ reduction in all-cause mortality in the CCB/ACEI group. This difference in outcome between the two groups could be partly explained by the $2.7 \mathrm{mmHg}$ average systolic $\mathrm{BP}$ difference throughout the trial, favoring the $\mathrm{CCB} / \mathrm{ACEI}$ group. However, and as discussed by the authors, this difference in BP would be expected then to generate a difference up to $8 \%$ in coronary events and up to $14 \%$ in strokes, based on the results of randomized trials and long-term prospective observational data. ${ }^{54}$ The Avoiding Cardiovascular Events in Combination Therapy in Patients Living with Systolic Hypertension (ACCOMPLISH) trial was a randomized, double-blind trial that aimed to compare the use of a fixed combination ACEI (benazepril)/CCB (AML) with an ACEI/ thiazide combination in 11,506 hypertensive patients with high CV risk. After 36 months, the ACEI/CCB fixed combination resulted in a $20 \%$ greater risk reduction in the primary outcome (a composite of $\mathrm{CV}$ events and death from $\mathrm{CV}$ causes). Interestingly, the difference in systolic BP between the two groups was less than $1 \mathrm{mmHg}$ over the course of the trial, suggesting a benefit on $\mathrm{CV}$ outcomes of the ACEI/CCB combination that went beyond BP lowering. ${ }^{35}$

A substudy of the ASCOT trial suggested that the advantage seen with this specific combination on $\mathrm{CV}$ outcomes might be explained by its ability to reduce central aortic pressures. ${ }^{55}$

Large clinical trials also have shown comparable efficacy on hard clinical outcomes when using an ARB as compared with ACEIs, but with better overall tolerability. ${ }^{41}$ In a recent multicenter, randomized prospective trial in Japanese patients with HTN at high CV risk, the addition of VAL to achieve BP target reduced the incidence of stroke by $45 \%$ compared with nonRAAS-based add-on therapy. ${ }^{56}$ No data with the DRI aliskiren (ALI) are available from large, outcome-driven clinical trials. ${ }^{57}$

\section{RAAS inhibitors and diuretics}

The addition of a diuretic to a RAAS inhibitor also leads to the additive BP-lowering effect and, as discussed earlier, to a better tolerability profile as opposed to that of each agent used alone..$^{20}$ Furthermore, the addition of a RAAS inhibitor will reduce the incidence of thiazide-induced new-onset diabetes..$^{58}$

Most outcome trials have used the thiazide-like diuretic chlorthalidone in head-to-head comparisons with other agents. ${ }^{59,60}$ Chlorthalidone has been shown to be more effective than HCTZ in maintaining 24-hour BP control, including better nighttime BP control. ${ }^{61}$ Therefore, chlorthalidone might be the preferred diuretic to combine with a RAAS inhibitor; however, most available SPCs use HCTZ. Recently, an SPC combining chlorthalidone and the ARB azilsartan was approved. ${ }^{62}$

Another thiazide-like diuretic, indapamide, was tested in two clinical trials. The Hypertension in the Very Elderly Trial (HYVET) was conducted to assess the benefits and risks of BP-lowering agents in the elderly population. This randomized, double-blind, placebo-controlled trial included around 4000 patients aged 80 years or older with persistent HTN (systolic BP $>160 \mathrm{mmHg}$ ). Patients in the active-treatment group received indapamide (sustained release, $1.5 \mathrm{mg}$ ) and perindopril ( $2 \mathrm{mg}$ and $4 \mathrm{mg}$ ) as needed to reach the target BP $(<150 / 80 \mathrm{mmHg})$. At the end of the trial, BP targets were reached in $20 \%$ of patients in the placebo group and $48 \%$ in the active treatment group. In addition, $73.5 \%$ of patients in the active-treatment group were receiving combination therapy (indapamide/perindopril) at trial closure. The active treatment group achieved a 30\% reduction in the rate of stroke, a 39\% reduction in the rate of death from stroke, and a $21 \%$ reduction in the rate of death from any cause. ${ }^{63}$ The ADVANCE trial was also a randomized, double-blind, placebo-controlled trial that aimed to assess the effects of an SPC of an ACEI (perindopril) and indapamide in a large population of patients with type 2 diabetes. The mean entry BP of randomized patients was $145 / 81 \mathrm{mmHg}$, and $41 \%$ had a BP less than $140 \mathrm{mmHg}$ systolic and $90 \mathrm{mmHg}$ diastolic. During follow-up, BP was reduced by an average of $5.6 \mathrm{mmHg}$ systolic and $2.2 \mathrm{mmHg}$ diastolic in patients assigned to the active treatment. After a mean follow-up of 4.3 years, the group assigned to perindopril/indapamide achieved a $9 \%$ relative risk reduction in major macrovascular and microvascular events. The relative risk for death from CV causes was reduced by $18 \%$, and that for death from any cause by $14 \% .^{64}$

\section{Acceptable combinations Beta-blockers/diuretics}

The use of beta-blockers and diuretics is well-established in the management of HTN, and their combination leads to an additive BP-lowering effect. ${ }^{46}$ However, this specific combination has recently fallen out of favor because of an increased risk for new-onset diabetes. It has been shown that diuretics are associated with a $32 \%$ increased risk for new-onset diabetes compared with placebo or non-betablocker antihypertensive agents; beta-blockers also have a $32 \%$ increased risk compared with placebo or nondiuretic antihypertensive agents. ${ }^{65}$ This combination is therefore 
Table 3 Currently approved combination therapy drugs ${ }^{77}$

\begin{tabular}{|c|c|c|}
\hline Components & Brand name & Dosage forms (mg) \\
\hline \multicolumn{3}{|l|}{ Dual combinations } \\
\hline \multicolumn{3}{|l|}{ RAAS inhibitor/CCB } \\
\hline Benazepril/amlodipine & Lotrel, Amlobenz & $10 / 2.5,10 / 5,20 / 5,40 / 5,20 / 10,40 / 10$ \\
\hline Enalapril/felodipine & Lexxel & $5 / 5$ \\
\hline Trandalopril/verapamil & Tarka & $2 / 180,1 / 240,2 / 240,4 / 240$ \\
\hline Valsartan/amlodipine & Exforge & $160 / 5,160 / 10,320 / 5,320 / 10$ \\
\hline Telmisartan/amlodipine & Twynsta & $40 / 5,40 / 10,80 / 5,80 / 10$ \\
\hline Olmesartan/amlodipine & Azor & $20 / 5,20 / 10,40 / 5,40 / 10$ \\
\hline Aliskiren/amlodipine & Tekamlo & $150 / 5,150 / 10,300 / 5,300 / 10$ \\
\hline \multicolumn{3}{|l|}{ RAAS inhibitor/diuretic } \\
\hline Moexipril/HCTZ & Uniretic & $7.5 / 12.5,15 / 12.5,15 / 25$ \\
\hline Lisinopril/HCTZ & Zestoretic, Prinzide & $10 / 12.5,20 / 12.5,20 / 25$ \\
\hline Quinapril/HCTZ & Accuretic, Quinaretic & $10 / I 2.5,20 / 12.5,20 / 25$ \\
\hline Captopril/HCTZ & Capozide & $25 / 15,25 / 25,50 / 15,50 / 25$ \\
\hline Benazepril/HCTZ & Lotensin HCT & $5 / 6.25,10 / 12.5,20 / 12.5,20 / 25$ \\
\hline Fosinopril/HCTZ & Monopril HCT & $10 / 12.5,20 / 12.5$ \\
\hline Enalapril/HCTZ & Vaseretic & $10 / 25$ \\
\hline Valsartan/HCTZ & Diovan HCT & $80 / 12.5,160 / 12.5,160 / 25,320 / 12.5,320 / 25$ \\
\hline Azilsartan medoxomil/chlorthalidone & Edarbyclor & $40 / 12.5,40 / 25$ \\
\hline Losartan/HCTZ & Hyzaar & $50 / 12.5,100 / 12.5,100 / 25$ \\
\hline Candesartan/HCTZ & Atacand HCT & $16 / 12.5,32 / 12.5,32 / 25$ \\
\hline Eprosartan/HCTZ & Teveten HCT & $600 / 12.5,600 / 25$ \\
\hline Telmisartan/HCTZ & Micardis HCT & $40 / 12.5,80 / 12.5,80 / 25$ \\
\hline Irbesartan/HCTZ & Avalide & $150 / 12.5,300 / 12.5,300 / 25$ \\
\hline Olmesartan/HCTZ & Benicar HCT & $20 / / 2.5,40 / 12.5,40 / 25$ \\
\hline Aliskiren/HCTZ & Tekturna HCT & $150 / 12.5,150 / 25,300 / 12.5,300 / 25$ \\
\hline \multicolumn{3}{|l|}{ Beta-blocker/diuretic } \\
\hline Nadolol/bendroflumethiazide & Corzide & $40 / 5,80 / 5$ \\
\hline Tenormin/chlorthalidone & Tenoretic & $50 / 25,100 / 25$ \\
\hline Bisoprolol/HCTZ & Ziac & $2.5 / 6.25,5 / 6.25,10 / 6.25$ \\
\hline Metoprolol/HCTZ & Dutoprol & $25 / 12.5,50 / 12.5,100 / / 2.5$ \\
\hline Metoprolol/HCTZ & Lopressor HCT & $50 / 25,100 / 25,100 / 50$ \\
\hline \multicolumn{3}{|l|}{ Thiazide diuretic/potassium-sparing diuretic } \\
\hline HCTZ/triamterene & Maxzide, Dyazide & $25 / 37.5,50 / 75$ \\
\hline HCTZ/spironolactone & Aldactazide & $25 / 25,50 / 50$ \\
\hline HCTZ/amiloride & Moduretic & $50 / 5$ \\
\hline \multicolumn{3}{|l|}{ Triple combinations } \\
\hline Amlodipine/valsartan/HCTZ & Exforge HCT & $5 / 160 / 12.5,10 / 160 / 12.5,5 / 160 / 25,10 / 160 / 25,10 / 320 / 25$ \\
\hline Amlodipine/olmesartan/HCTZ & Tribenzor & $5 / 20 / 12.5,5 / 40 / 12.5,5 / 40 / 25,10 / 40 / 12.5,10 / 40 / 25$ \\
\hline Amlodipine/aliskiren/HCTZ & Amturnide & $5 / 150 / 12.5,5 / 300 / 12.5,5 / 300 / 25,10 / 300 / 12.5,10 / 300 / 25$ \\
\hline
\end{tabular}

Abbreviations: RAAS, renin-angiotensin-aldosterone system; CCB, calcium channel blocker; HCTZ, hydrochlorothiazide.

not recommended in patients with metabolic syndrome or prediabetes or who are at high risk for diabetes. ${ }^{10}$ In addition, both diuretics and beta-blockers are known to negatively affect erectile function. ${ }^{66}$

\section{$\mathrm{CCB} /$ diuretics}

Because of the natriuretic properties of $\mathrm{CCBs}$, the combination of a $\mathrm{CCB}$ and a diuretic results in a partially additive BPlowering effect. ${ }^{67}$ However, in the VALUE trial, the addition of HCTZ as a second step to AML achieved similar BP reduction compared with that seen in the VAL/HCTZ group, was well-tolerated, and resulted in a similar reduction in the primary composite outcome of CV mortality and morbidity. ${ }^{68}$ Therefore, this combination is classified as acceptable; however, it is not currently available as an SPC.

\section{CCB/beta-blockers}

The addition of a dihydropyridine CCB to a beta-blocker will result in a complementary and additive BP-lowering effect. ${ }^{48}$ No large outcome trial assessed this specific combination; however, a beta-blocker added to felodipine was the second combination used to achieve BP targets in the Hypertension Optimal Treatment (HOT) study. The HOT study was one of the largest trials in HTN to establish the benefits of tight BP 


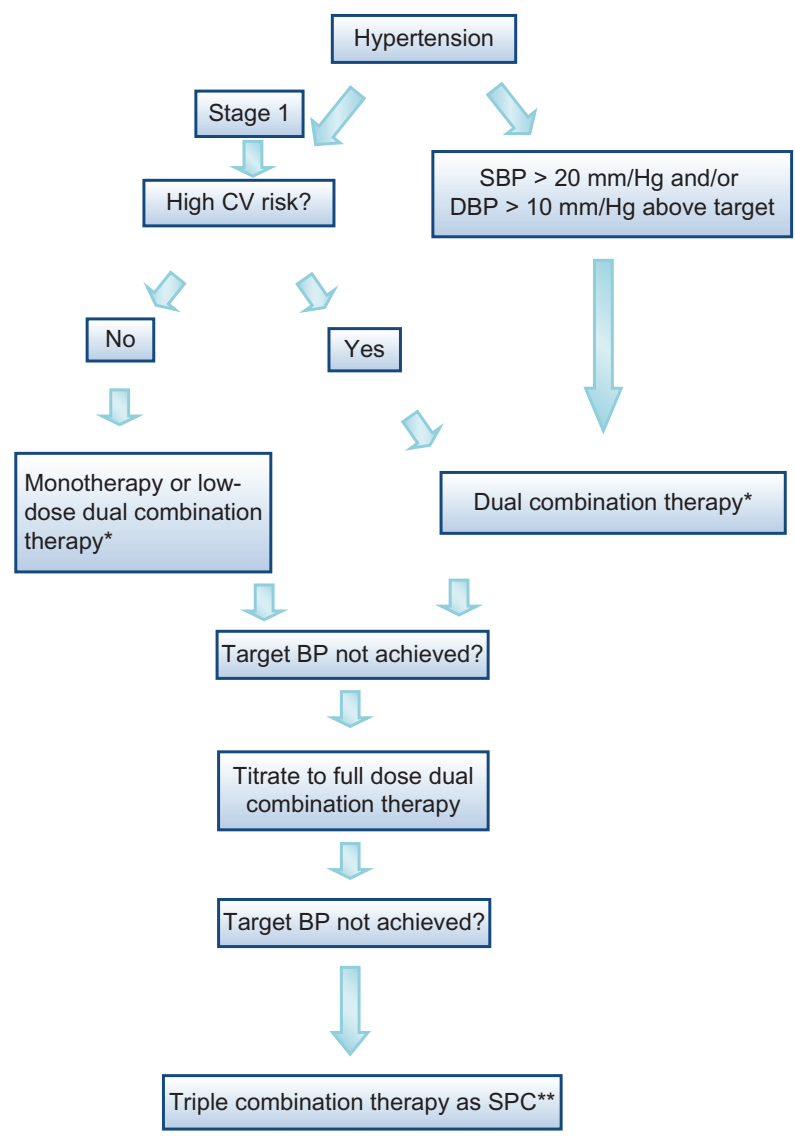

Figure I Approach for HTN management, using combination therapy. . $^{10,11,20,71-76}$ Notes: *Only use preferred and acceptable dual-combination (Table 2) and, preferably, SPC; **if BP target is not achieved on triple SPC, consider secondary causes of hypertension and add a fourth BP-lowering drug if needed.

Abbreviations: CV, cardiovascular; SBP, systolic blood pressure; DBP, diastolic blood pressure; BP, blood pressure; SPC, single pill combination.

control on $\mathrm{CV}$ outcomes. ${ }^{36} \mathrm{~A}$ combination of bisoprolol and AML as an SPC is currently available in many countries.

\section{Dual calcium channel blockade}

The addition of a dihydropyridine $\mathrm{CCB}$ to a nondihydropyridine $\mathrm{CCB}$ such as diltiazem or verapamil results in an additive BPlowering effect. ${ }^{69}$ In a recent meta-analysis, this strategy of dual calcium channel blockade was more effective at lowering $\mathrm{BP}$, compared with CCB monotherapy, and was well-tolerated. However, long-term outcome data on safety and efficacy of this specific combination are currently lacking. ${ }^{70}$

\section{Triple SPCs}

As mentioned earlier, about $24 \%$ to $32 \%$ of patients with HTN will require more than two drugs to achieve their BP target. ${ }^{35,36}$ On the basis of the inherent advantages of an SPC, as described earlier, using SPCs containing three BP-lowering drugs may be a good alternative for these patients, although it is not currently recommended as initial therapy. On the basis of available evidence and beneficial clinical outcome data as outlined earlier, a rational combination in this setting would be an RAAS inhibitor, a CCB, and a diuretic. ${ }^{11}$ In fact, three SPCs combining these agents have been approved for use, based on large clinical trials composed of VAL/AML/HCTZ, olmesartan (OM)/AML/HCTZ, and ALI/AML/HCTZ.

A prospective, randomized, double-blind trial aimed to assess the efficacy and safety of an SPC containing VAL/ AML/HCTZ compared with a dual-combination SPC of the same components (VAL/AML, VAL/HCTZ, and AML/ HCTZ) in 2271 patients with stage 2 HTN. At the end of this 12-week study, significantly more patients achieved BP target in the triple-therapy group (about $70 \%$ of patients) compared with in the dual-combination groups (around 50\% of patients). In addition, the triple-combination therapy was well-tolerated, with reportedly less peripheral edema. ${ }^{71}$

In the TRINITY (triple therapy with Olmesartan Medoxomil, Amlodipine, and Hydrochlorothiazide in hypertensive patients study) trial, the efficacy and tolerability of a triple SPC containing OM/AML/HCTZ was compared with the components' dual combinations (OM/AML, OM/ HCTZ, and AML/HCTZ) in patients with moderate to severe HTN. At 12 weeks, the triple-combination therapy resulted in significantly more BP reduction when compared with dual therapy, with no significant difference in adverse events. ${ }^{72}$ The 24-hour ambulatory BP substudies of the two trials discussed here confirmed significantly larger reductions in mean 24-hour, daytime, and nighttime systolic and diastolic $\mathrm{BP}$ in the triple-combination groups. ${ }^{73,74}$ Furthermore, in an open-label extension of the TRINITY trial, the triplecombination therapy allowed up to $80 \%$ of patients to achieve BP target after 52 weeks and was well-tolerated. ${ }^{75}$ In another trial, similar results were observed with an SPC containing ALI/AML/HCTZ. ${ }^{76}$

These trials provide proof of the safety and efficacy of triple SPCs in the management of HTN and provide the rationale for their use in patients who fail initial dualcombination therapy. Bearing in mind the inherent advantages of a single pill, as discussed earlier, these combinations might be an attractive option in patients with HTN who do not achieve BP target on dual drug combinations. The longterm benefit of this strategy on $\mathrm{CV}$ outcomes will have to be confirmed by clinical trials.

\section{Conclusion}

In conclusion, and based on the best available evidence, combination therapy will eventually be needed for a vast majority of patients with HTN and should be the first-line 
treatment for patients with a systolic BP more than $20 \mathrm{mmHg}$ and/or a diastolic BP more than $10 \mathrm{mmHg}$ above target and for those with high $\mathrm{CV}$ risk. Low-dose combination therapy may be the preferred initial approach for most newly diagnosed patients with HTN. ${ }^{9-11,20}$

It also should be emphasized that using SPCs might be the best way to deliver combination therapy, given their inherent advantages, particularly increased compliance and better overall tolerability. Currently approved SPCs (Table 3), composed of components that are well established as monotherapy and in combination in large clinical trials, offer to the treating physician a wide array of dual- and triple-combination therapies that will help patients achieve BP targets. Figure 1 provides a practical strategy for HTN management. The effect of such a strategy on overall BP control and its effect on further reducing CV events and targetorgan damage in the hypertensive population, as compared with the conventional approach, will need to be confirmed by future clinical and population-based studies.

\section{Disclosure}

The authors report no conflicts of interest in this work.

\section{References}

1. Kearney PM, Whelton M, Reynolds K, Muntner P, Whelton PK, He J. Global burden of hypertension: analysis of worldwide data. Lancet. 2005;365(9455):217-223.

2. Centers for Disease Control and Prevention (CDC). Vital signs: prevalence, treatment, and control of hypertension - United States, 1999-2002 and 2005-2008. MMWR Morb Mortal Wkly Rep. 2011;60(4): 103-108.

3. Roger VL, Go AS, Lloyd-Jones DM, et al; for American Heart Association Statistics Committee and Stroke Statistics Subcommittee. Heart disease and stroke statistics - 2012 update: a report from the American Heart Association. Circulation. 2012;125(1):e2-e220.

4. Levy D, Larson MG, Vasan RS, Kannel WB, Ho KK. The progression from hypertension to congestive heart failure. JAMA. 1996;275(20): $1557-1562$.

5. Criqui MH, Langer RD, Fronek A, et al. Mortality over a period of 10 years in patients with peripheral arterial disease. $N$ Engl J Med. 1992; 326(6):381-386.

6. Klag MJ, Whelton PK, Randall BL, et al. Blood pressure and end-stage renal disease in men. $N$ Engl J Med. 1996;334(1):13-18.

7. Danaei G, Finucane MM, Lin JK, et al; for Global Burden of Metabolic Risk Factors of Chronic Diseases Collaborating Group (Blood Pressure). National, regional, and global trends in systolic blood pressure since 1980: systematic analysis of health examination surveys and epidemiological studies with 786 country-years and 5.4 million participants. Lancet. 2011; 377(9765):568-577.

8. Morgan TO, Anderson AI, MacInnis RJ. ACE inhibitors, beta-blockers, calcium blockers, and diuretics for the control of systolic hypertension. Am J Hypertens. 2001;14(3):241-247.

9. Chobanian AV, Bakris GL, Black HR, et al; for Joint National Committee on Prevention, Detection, Evaluation, and Treatment of High Blood Pressure. National Heart, Lung and Blood Institute; National High Blood Pressure Education Program Coordinating Committee. Seventh report of the Joint National Committee on Prevention, Detection, Evaluation, and Treatment of High Blood Pressure. Hypertension. 2003;42(6): 1206-1252.
10. Mancia G, De Backer G, Dominiczak A, et al; for The task force for the management of arterial hypertension of the European Society of Hypertension, the task force for the management of arterial hypertension of the European Society of Cardiology. 2007 Guidelines for the management of arterial hypertension: The Task Force for the Management of Arterial Hypertension of the European Society of Hypertension (ESH) and of the European Society of Cardiology (ESC). Eur Heart J. 2007;28(12):1462-1536.

11. Mancia G, Laurent S, Agabiti-Rosei E, et al; for European Society of Hypertension. Reappraisal of European guidelines on hypertension management: a European Society of Hypertension Task Force document. J Hypertens. 2009;27(11):2121-2158.

12. Law MR, Wald NJ, Morris JK, Jordan RE. Value of low dose combination treatment with blood pressure lowering drugs: analysis of 354 randomised trials. BMJ. 2003;326(7404):1427.

13. Wald DS, Law M, Morris JK, Bestwick JP, Wald NJ. Combinatory therapy versus monotherapy in reducing blood pressure: meta-analysis on 11,000 participants from 42 trials. Am J Med. 2009;122(3):290-300.

14. Byrd JB, Zeng C, Tavel HM, et al. Combination therapy as initial treatment for newly diagnosed hypertension. Am Heart J. 2011;162(2): 340-346.

15. Weber MA, Julius S, Kjeldsen SE, et al. Blood pressure dependent and independent effects of antihypertensive treatment on clinical events in the VALUE Trial. Lancet. 2004;363(9426):2049-2051.

16. Nasser SA, Lai Z, O’Connor S, Liu X, Flack JM. Does earlier attainment of blood pressure goal translate into fewer cardiovascular events? Curr Hypertens Rep. 2008;10(5):398-404.

17. Fogari R, Zoppi A, Ferrari I, Mugellini A, Preti P, Derosa G. Time to achieve blood pressure goal with a combination versus a conventional monotherapy approach in hypertensive patients with metabolic syndrome. Clin Exp Hypertens. 2010;32(5):245-250.

18. Gradman AH, Parisé H, Lefebvre P, Falvey H, Lafeuille MH, Duh MS. Initial combination therapy reduces the risk of cardiovascular events in hypertensive patients: a matched cohort study. Hypertension. 2013; 61(2):309-318.

19. Weir MR, Levy D, Crikelair N, Rocha R, Meng X, Glazer R. Time to achieve blood-pressure goal: influence of dose of valsartan monotherapy and valsartan and hydrochlorothiazide combination therapy. Am J Hypertens. 2007;20(7):807-815.

20. Gradman AH, Basile JN, Carter BL, Bakris GL; for American Society of Hypertension Writing Group. Combination therapy in hypertension. J Am Soc Hypertens. 2010;4(1):42-50.

21. Xie HH, Shen FM, Xu LP, Han P, Miao CY, Su DF. Reduction of blood pressure variability by combination therapy in spontaneously hypertensive rats. J Hypertens. 2007;25(11):2334-2344.

22. Ling G, Liu AJ, Shen FM, Cai GJ, Liu JG, Su DF. Effects of combination therapy with atenolol and amlodipine on blood pressure control and stroke prevention in stroke-prone spontaneously hypertensive rats. Acta Pharmacol Sin. 2007;28(11):1755-1760.

23. Rothwell PM, Howard SC, Dolan E, et al. Prognostic significance of visit-to-visit variability, maximum systolic blood pressure, and episodic hypertension. Lancet. 2010;375(9718):895-905.

24. Sever PS, Messerli FH. Hypertension management 2011: optimal combination therapy. Eur Heart J. 2011;32(20):2499-2506.

25. Sica DA. Rationale for fixed-dose combinations in the treatment of hypertension: the cycle repeats. Drugs. 2002;62(3):443-462.

26. Makani H, Bangalore S, Romero J, Wever-Pinzon O, Messerli FH. Effect of renin-angiotensin system blockade on calcium channel blockerassociated peripheral edema. Am J Med. 2011;124(2):128-135.

27. Ebbutt AF, Elsdon-Dew RW. A multicentre study examining the substitution of Trasidrex for the free combination of Slow-Trasicor and Navidrex-K. J Int Med Res. 1979;7(6):524-527.

28. Schweizer J, Hilsmann U, Neumann G, Handrock R, Klebs S. Efficacy and safety of valsartan 160/HCTZ $25 \mathrm{mg}$ in fixed combination in hypertensive patients not controlled by candesartan $32 \mathrm{mg}$ plus HCTZ $25 \mathrm{mg}$ in free combination. Curr Med Res Opin. 2007;23(11): $2877-2885$. 
29. Mancia G, Omboni S; for CARDIO (CAndesaRtan combined with DIuretic in hypertensiOn) Study Group. Candesartan plus hydrochlorothiazide fixed combination vs previous monotherapy plus diuretic in poorly controlled essential hypertensive patients. Blood Press Suppl. 2004;2:11-17.

30. Gupta AK, Arshad S, Poulter NR. Compliance, safety, and effectiveness of fixed-dose combinations of antihypertensive agents: a meta-analysis. Hypertension. 2010;55(2):399-407.

31. Dezii CM. A retrospective study of persistence with single-pill combination therapy vs concurrent two-pill therapy in patients with hypertension. Manag Care. 2000;9(Suppl 9):2-6.

32. Rudd P. Clinicians and patients with hypertension: unsettled issues about compliance. Am Heart J. 1995;130(3 Pt 1):572-579.

33. Kettani FZ, Dragomir A, Côté R, et al. Impact of a better adherence to antihypertensive agents on cerebrovascular disease for primary prevention. Stroke. 2009;40(1):213-220.

34. Breekveldt-Postma NS, Penning-van Beest FJ, Siiskonen SJ, et al. The effect of discontinuation of antihypertensives on the risk of acute myocardial infarction and stroke. Curr Med Res Opin. 2008;24(1): 121-127.

35. Jamerson K, Weber MA, Bakris GL, et al; for ACCOMPLISH Trial Investigators. Benazepril plus amlodipine or hydrochlorothiazide for hypertension in high-risk patients. $N$ Engl J Med. 2008; 359(23):2417-2428.

36. Hansson L, Zanchetti A, Carruthers SG, et al. Effects of intensive blood-pressure lowering and low-dose aspirin in patients with hypertension: principal results of the Hypertension Optimal Treatment (HOT) randomised trial. HOT Study Group. Lancet. 1998;351(9118): 1755-1762.

37. Dresser GK, Feldman RD. New trends in hypertension management: of salt, going solo and single pill combos. Curr Opin Cardiol. 2010; 25(4):342-349.

38. de la Sierra A, Barrios V. Blood pressure control with angiotensin receptor blocker-based three-drug combinations: key trials. Adv Ther. 2012;29(5):401-415.

39. Coleman TG, Hall JE. Systemic hemodynamics and regional blood flow regulation. In: Izzo JL Jr, Black HR, Sica DA, editors. Hypertension Primer, 4th ed. Philadelphia PA: Lippincott, Williams and Wilkins; 2008:129-132.

40. Mehta JL, Lopez LM. Rebound hypertension following abrupt cessation of clonidine and metoprolol. Treatment with labetalol. Arch Intern Med. 1987;147(2):389-390.

41. Yusuf S, Teo KK, Pogue J, et al; for ONTARGET Investigators. Telmisartan, ramipril, or both in patients at high risk for vascular events. N Engl J Med. 2008;358(15):1547-1559.

42. Parving HH, Brenner BM, McMurray JJ, et al; for ALTITUDE Investigators. Cardiorenal end points in a trial of aliskiren for type 2 diabetes. N Engl J Med. 2012;367(23):2204-2213.

43. Taddei S. Fixed-dose combination therapy in hypertension: pros. High Blood Press Cardiovasc Prev. 2012;19(2):55-57.

44. Ambrosioni E, Borghi C, Costa FV. Captopril and hydrochlorothiazide: rationale for their combination. Br J Clin Pharmacol. 1987;23 Suppl 1: 43S-50S.

45. Frishman WH, Ram CV, McMahon FG, et al. Comparison of amlodipine and benazepril monotherapy to amlodipine plus benazepril in patients with systemic hypertension: a randomized, double-blind, placebo-controlled, parallel-group study. The Benazepril/Amlodipine Study Group. J Clin Pharmacol. 1995;35(11): 1060-1066.

46. Lacourcière Y, Arnott W. Placebo-controlled comparison of the effects of nebivolol and low-dose hydrochlorothiazide as monotherapies and in combination on blood pressure and lipid profile in hypertensive patients. J Hum Hypertens. 1994;8(4):283-288.

47. Dahlöf B, Degl' Innocenti A, Elmfeldt D, et al. Felodipine-metoprolol combination tablet: maintained health-related quality of life in the presence of substantial blood pressure reduction. Am J Hypertens. 2005;18(10):1313-1319.
48. Frishman WH, Hainer JW, Sugg J; for M-FACT Study Group. A factorial study of combination hypertension treatment with metoprolol succinate extended release and felodipine extended release results of the Metoprolol Succinate-Felodipine Antihypertension Combination Trial (M-FACT). Am J Hypertens. 2006;19(4):388-395.

49. Wing LM, Chalmers JP, West MJ, et al. Enalapril and atenolol in essential hypertension: attenuation of hypotensive effects in combination. Clin Exp Hypertens A. 1988;10(1):119-133.

50. Hunt SA, Abraham WT, Chin MH, et al. 2009 focused update incorporated into the ACC/AHA 2005 Guidelines for the Diagnosis and Management of Heart Failure in Adults: a report of the American College of Cardiology Foundation/American Heart Association Task Force on Practice Guidelines: developed in collaboration with the International Society for Heart and Lung Transplantation. Circulation. 2009;119(14):e391-e479.

51. Antman EM, Hand M, Armstrong PW, et al; for Canadian Cardiovascular Society, American Academy of Family Physicians, American College of Cardiology, American Heart Association. 2007 focused update of the ACC/AHA 2004 guidelines for the management of patients with ST-elevation myocardial infarction: a report of the American College of Cardiology/American Heart Association Task Force on Practice Guidelines. J Am Coll Cardiol. 2008;51(2):210-247.

52. Gradman AH, Cutler NR, Davis PJ, Robbins JA, Weiss RJ, Wood BC. Combined enalapril and felodipine extended release (ER) for systemic hypertension. Enalapril-Felodipine ER Factorial Study Group. Am J Cardiol. 1997;79(4):431-435.

53. Krakoff LR. Diuretics for hypertension. Circulation. 2005;112(10): e127-e129.

54. Dahlöf B, Sever PS, Poulter NR, et al; for ASCOT Investigators. Prevention of cardiovascular events with an antihypertensive regimen of amlodipine adding perindopril as required versus atenolol adding bendroflumethiazide as required, in the Anglo-Scandinavian Cardiac Outcomes Trial-Blood Pressure Lowering Arm (ASCOT-BPLA): a multicentre randomised controlled trial. Lancet. 2005;366(9489):895-906.

55. Williams B, Lacy PS, Thom SM, et al; for Anglo-Scandinavian Cardiac Outcomes Trial Investigators; CAFE Steering Committee and Writing Committee. Differential impact of blood pressure-lowering drugs on central aortic pressure and clinical outcomes: principal results of the Conduit Artery Function Evaluation (CAFE) study. Circulation. 2006;113(9):1213-1225.

56. Sawada T, Yamada H, Dahlöf B, Matsubara H; for KYOTO HEART Study Group. Effects of valsartan on morbidity and mortality in uncontrolled hypertensive patients with high cardiovascular risks: KYOTO HEART Study. Eur Heart J. 2009;30(20):2461-2469.

57. Gradman AH, Kad R. Renin inhibition in hypertension. J Am Coll Cardiol. 2008;51(5):519-528.

58. Alderman $\mathrm{MH}$. New onset diabetes during antihypertensive therapy. Am J Hypertens. 2008;21(5):493-499.

59. Cushman WC, Ford CE, Cutler JA, et al; for ALLHAT Collaborative Research Group. Success and predictors of blood pressure control in diverse North American settings: the antihypertensive and lipidlowering treatment to prevent heart attack trial (ALLHAT). J Clin Hypertens (Greenwich). 2002;4(6):393-404.

60. [No authors listed] Prevention of stroke by antihypertensive drug treatment in older persons with isolated systolic hypertension. Final results of the Systolic Hypertension in the Elderly Program (SHEP). SHEP Cooperative Research Group. JAMA. 1991;265(24):3255-3264.

61. Ernst ME, Carter BL, Goerdt CJ, et al. Comparative antihypertensive effects of hydrochlorothiazide and chlorthalidone on ambulatory and office blood pressure. Hypertension. 2006;47(3):352-358.

62. Cushman WC, Bakris GL, White WB, et al. Azilsartan medoxomil plus chlorthalidone reduces blood pressure more effectively than olmesartan plus hydrochlorothiazide in stage 2 systolic hypertension. Hypertension. 2012;60(2):310-318.

63. Beckett NS, Peters R, Fletcher AE, et al; for the HYVET Study Group. Treatment of hypertension in patients 80 years of age or older. $N$ Engl J Med. 2008;358(18):1887-1898. 
64. Patel A, MacMahon S, Chalmers J, et al; for ADVANCE Collaborative Group. Effects of a fixed combination of perindopril and indapamide on macrovascular and microvascular outcomes in patients with type 2 diabetes mellitus (the ADVANCE trial): a randomised controlled trial. Lancet. 2007;370(9590):829-840.

65. Messerli FH, Bangalore S, Julius S. Risk/benefit assessment of betablockers and diuretics precludes their use for first-line therapy in hypertension. Circulation. 2008;117(20):2706-2715.

66. Doumas M, Douma S. The effect of antihypertensive drugs on erectile function: a proposed management algorithm. J Clin Hypertens (Greenwich). 2006;8(5):359-364.

67. Salvetti A, Magagna A, Innocenti P, et al. The combination of chlorthalidone with nifedipine does not exert an additive antihypertensive effect in essential hypertensives: a crossover multicenter study. J Cardiovasc Pharmacol. 1991;17(2):332-335.

68. Julius S, Kjeldsen SE, Weber M, et al; for VALUE trial group. Outcomes in hypertensive patients at high cardiovascular risk treated with regimens based on valsartan or amlodipine: the VALUE randomised trial. Lancet. 2004;363(9426):2022-2031.

69. Saseen JJ, Carter BL, Brown TE, Elliott WJ, Black HR. Comparison of nifedipine alone and with diltiazem or verapamil in hypertension. Hypertension. 1996;28(1):109-114.

70. Alviar CL, Devarapally S, Nadkarni GN, et al. Efficacy and safety of dual calcium channel blockade for the treatment of hypertension: a meta-analysis. Am J Hypertens. 2013;26(2):287-297.

71. Calhoun DA, Lacourcière Y, Chiang YT, Glazer RD. Triple antihypertensive therapy with amlodipine, valsartan, and hydrochlorothiazide: a randomized clinical trial. Hypertension. 2009; 54(1):32-39.
72. Oparil S, Melino M, Lee J, Fernandez V, Heyrman R. Triple therapy with olmesartan medoxomil, amlodipine besylate, and hydrochlorothiazide in adult patients with hypertension: The TRINITY multicenter, randomized, double-blind, 12-week, parallel-group study. Clin Ther. 2010;32(7):1252-1269.

73. Lacourcière Y, Crikelair N, Glazer RD, Yen J, Calhoun DA. 24-Hour ambulatory blood pressure control with triple-therapy amlodipine, valsartan and hydrochlorothiazide in patients with moderate to severe hypertension. J Hum Hypertens. 2011;25(10):615-622.

74. Izzo JL Jr, Chrysant SG, Kereiakes DJ, et al. 24-hour efficacy and safety of triple-combination therapy with olmesartan, amlodipine, and hydrochlorothiazide: the TRINITY ambulatory blood pressure substudy. J Clin Hypertens (Greenwich). 2011;13(12):873-880.

75. Kereiakes DJ, Chrysant SG, Izzo JL Jr, et al. Long-term efficacy and safety of triple-combination therapy with olmesartan medoxomil and amlodipine besylate and hydrochlorothiazide for hypertension. J Clin Hypertens (Greenwich). 2012;14(3):149-157.

76. Ferdinand KC, Weitzman R, Israel M, Lee J, Purkayastha D, Jaimes EA. Efficacy and safety of aliskiren-based dual and triple combination therapies in US minority patients with stage 2 hypertension. J Am Soc Hypertens. 2011;5(2):102-113.

77. Drugs.com. Antihypertensive combinations [webpage on the Internet]. Drugs.com; 2013. Available from: http://www.drugs.com/drug-class/ antihypertensive-combinations.html. Accessed January 20, 2013.
Integrated Blood Pressure Control

\section{Publish your work in this journal}

Integrated Blood Pressure Control is an international, peer-reviewed open-access journal focusing on the integrated approach to managing hypertension and risk reduction. Treating the patient and comorbidities together with diet and lifestyle modification and optimizing healthcare resources through a multidisciplinary team approach constitute key

\section{Dovepress}

features of the journal. This journal is indexed on American Chemical Society's Chemical Abstracts Service (CAS). The manuscript management system is completely online and includes a very quick and fair peerreview system, which is all easy to use. Visit http://www.dovepress.com/ testimonials.php to read real quotes from published authors 